Article

\title{
Spatiotemporal Analysis of Heavy Metal Water Pollution in Transitional China
}

\section{Huixuan Li ${ }^{1}$, Yingru Li ${ }^{2, *}$, Ming-Kuo Lee ${ }^{1}$, Zhongwei Liu ${ }^{3}$ and Changhong Miao ${ }^{4, *}$}

1 Department of Geosciences, Auburn University, Auburn, AL 36849, USA; E-Mails: lihuixuan90528@gmail.com (H.L.); leeming@auburn.edu (M.-K.L.)

2 Department of Sociology, University of Central Florida, Orlando, FL 32816, USA

3 Department of Geography and Regional Planning, Indiana University of Pennsylvania, Indiana, PA 15705, USA; E-Mail: zhwliu@gmail.com

4 Key Research Institute of Yellow River Civilization and Sustainable Development \& Collaborative Innovation Center on Yellow River Civilization of Henan Province, Henan University, Kaifeng 475004, China

* Authors to whom correspondence should be addressed; E-Mails: yingruli@yahoo.com (Y.L.); chhmiao@henu.edu.cn (C.M.); Tel.: +1-407-823-3744 (Y.L.); +86-371-2282-6115 (C.M.); Fax: +1-407-823-3026 (Y.L.); +86-371-2282-6085 (C.M.).

Academic Editor: Marc A. Rosen

Received: 9 May 2015 / Accepted: 2 July 2015 / Published: 13 July 2015

\begin{abstract}
China's socioeconomic transitions have dramatically accelerated its economic growth in last three decades, but also companioned with continuous environmental degradation. This study will advance the knowledge of heavy metal water pollution in China from a spatial-temporal perspective. Specifically, this study addressed the following: (1) spatial patterns of heavy metal water pollution levels were analyzed using data of prefecture-level cities from 2004 to 2011; and (2) spatial statistical methods were used to examine the underlying socioeconomic and physical factors behind water pollution including socioeconomic transitions (industrialization, urbanization, globalization and economic development), and environmental characteristic (natural resources, hydrology and vegetation coverage). The results show that only $\mathrm{Cr}$ pollution levels increased over the years. The individual pollution levels of the other four heavy metals, $\mathrm{As}, \mathrm{Cd}, \mathrm{Hg}$, and $\mathrm{Pb}$, declined. High heavy metal water pollution levels are closely associated with both anthropogenic activities and physical environments, in particular abundant mineral resources and industrialization prosperity. On the other hand, economic development and urbanization play important roles in controlling water pollution problems. The analytical findings will provide valuable information for
\end{abstract}


policy-makers to initiate and adjust protocols and strategies for protecting water sources and controlling water pollution; thus improving the quality of living environments.

Keywords: heavy metals; water pollution; Geographic information system (GIS); China

\section{Introduction}

China's socioeconomic transitions have dramatically accelerated its economic growth in the last three decades, but also companioned with continuous environmental degradation. Water is the source of life; China is facing serious shortages of water resources. The total amount of water resources in China ranks fourth in the world; however, the water supply per capita is only one-fourth of the world average [1,2]. The spatial mismatch between distributions of water resources, population, and economic activities has aggravated the water shortage problem [3]. For instance, only $8 \%$ of China's water resource is distributed in the populous North China Plain, which accounts for about 1/3 of GDP and 1/5 of the population. About 400 out of 668 Chinese cities are facing water shortages [4]. Severe water pollution issues caused by anthropogenic pollutant discharges, especially from heavy metals, further deteriorated the water shortage problem. According to a nationwide water quality survey [5], water from $64.2 \%$ of the river sections, $58.8 \%$ of the major lake areas, and $23.2 \%$ of the ground water wells met the national drinking water quality standard. Heavy metal contamination in water bodies can cause long-term human health risks creating significant consequences in Chinese economic development, and limiting environmental sustainability [6,7]. According to Liu's study [8], a rapidly rising mortality rate of cancer and high concentration of cancer incidences have formed 459 cancer villages across China. The author demonstrated that industrial wastewater should take the main responsibility for this phenomenon, because cancer incidences were highly clustered along China's water bodies, where many factories are located. The number of scandals due to heavy metal pollution crises also increased, such as lead poisoned hundred children through contaminated drinking water in Shaanxi Province in 2009, cadmium contaminated rice in Hunan 2013, etc. [9,10]. Given the academic and political concerns, investigating heavy metal water pollution and its driven forces has become a hot research topic.

Water pollution issues in China have attracted more attention since the 1990s, along with China's rapid economic growth as well as industrialization and urbanization processes [11,12]. Increasing public concerns about heavy metal pollution have led to extensive studies regarding China's water sustainability [2,10,12-18]. For example, Zhong et al. [19] investigated the relationship of heavy metal contamination among water, paddy soil and rice in Xiangyin County, in south central China. They provided scientific evidence informing residents and local governments to take action to control water pollution and preserve drinking water quality to reduce impacts on human health. Meng et al. [20] analyzed pollution levels of seven heavy metals (arsenic, cadmium, chromium, copper, mercury, lead, and zinc) in Bohai Bay. Yang and Liu [21] divided heavy metal pollutants into carcinogenic and non-carcinogenic categories to investigate pollution levels from tributaries of the Haihe River, China. Most previous studies have focused on one specific region, such as a river or a province, in China [2,10,11,15-18,20,22], while research concerning spatiotemporal patterns of water pollution across Mainland China are limited and merit further investigation. 
Generally, the spatial distribution of heavy metal contamination in water is determined by both human activities and natural conditions [23]. The main anthropogenic sources of China's heavy metal water pollution include industrial and municipal wastewaters, household sewage, and agricultural emissions [3,6]. Since the economic reform in 1978, China has been experiencing the socioeconomic transitions of industrialization, urbanization, and globalization, which have reshaped this country from many perspectives [24,25] including environmental degradation. The scale, intensity and speed of China's industrialization have caused severe water pollution with the rapid expansion of large-scale energy and mining production as well as small-scale rural manufacturing plants with very limited wastewater treatment capacity $[3,26]$. Industry has contributed about two-thirds of the total waste discharge into surface water and most of the untreated discharge comes from rural industries [26]. Industrial wastewater is one of the most serious and common sources of heavy metal with its high toxicity characteristics [12,26]. Moreover, to accelerate its economic growth, China has listed car production as one of its four "pillar industries", which has led to an explosive growth in transportation network and number of vehicles [6]. Transportation spills and emissions have heavily exacerbated air and soil pollutions and further polluted water through air pollutant settlement and soil contamination [27,28].

In the past three decades, the urban population in China has been tripled. Urban expansion has been identified as a main contributor to increasing non-point source pollution and heavy metal contamination of water [26,28]. Municipal sewage contributes significantly to ecotoxicological effects on water bodies [14]. The studies regarding the relationship between globalization and China's pollution show inconsistent results [29] due to spatial heterogeneity. On the one hand, the self-regulation of environmental performance has been increased in the developed coastal region, as foreign firms are more environmentally friendly and foreign investment may bring advanced environmental management [29,30]. On the other hand, the underdeveloped inland regions create pollution havens for foreign exporters to offset geographical and economic disadvantages and attract foreign investment [31]. Given that China is a large agricultural country, the extensive use of pesticides and fertilizers is of great concern for surface and ground water contamination.

In addition, such natural conditions as hydrologic characteristics of water bodies, natural mineral reserves, and greenery coverage also profoundly influence the heavy metal levels in water [20,32,33]. Generally, the pollution levels in downstream tend to be higher than in upstream, considering river channels may receive and collect contaminants from their small tributaries upstream. Moreover, more contaminants are released from highly industrialized areas in downstream watersheds. For example, in the coastal region of China, major cities such as Guangzhou and Hong Kong often have the worst contaminated watersheds [17]. Li et al. [34] analyzed 72 major metal ore reserves and mining areas in 22 provinces and found high level of heavy metals in watersheds associated with natural ore deposits or mining activities. Green areas, such as grass and forest, have also shown positive influence on water quality [33]. Previous studies mainly deliberated on a single factor in a local area [21]. In fact, the cumulative risk factors have greater impacts than individual factors.

The goal of this research is to investigate the spatiotemporal variation of heavy metal water pollution of China's major cities, and explore the underlying socioeconomic and environmental factors causing the pollution under the background of China's transitions. The next section outlines a discussion of data and methodology. Then the spatiotemporal variation of heavy metal water pollution levels against the 
background of socioeconomic transitions and natural conditions is examined and highlighted. Finally, we conclude with major findings.

\section{Experimental Section}

\subsection{Study Area}

Mainland China has 31 provincial-level units, including 4 municipalities (Beijing, Tianjin, Shanghai and Chongqing) and 27 provinces (Figure 1). They are traditionally grouped into three regions: eastern, central and western [25]. The eastern region plays a leading role in economic development, especially considering its strong advantages in attracting foreign trading partners and investment. This region has also benefits from the government's preferential policies as well as favorable natural environment and geographic location. The central region is highly populated and serves as the center of China's agricultural economy. The western region has complex and vast terrain with sparse population. Although less developed, the large land area and rich mineral resources provide the western region with great opportunities for potential development. China's administrative system is conveyed through multiple levels of governments, consisting of provinces, prefecture-level cities, county, and townships [35]. Prefecture-level cities were chosen as analytical units since they are formal cities, which have a well-defined metropolitan area [36]. Generally, prefecture-level cities are large administrative units containing one or more urban districts serving as the central urban area and often surrounded by a number of rural counties. The main fresh water resources in China include rivers and lake systems (Figure 1). China's major rivers include Yangtze River (Changjiang), Yellow River (Huang He), Pearl River (Zhujiang), Huaihe River, Liaohe River, and the Songhua River. The major lakes include Qinghai Lake (saltwater lake), Poyang Lake, Dongting Lake, Taihu Lake, and Hongze Lake (freshwater lakes) [37].

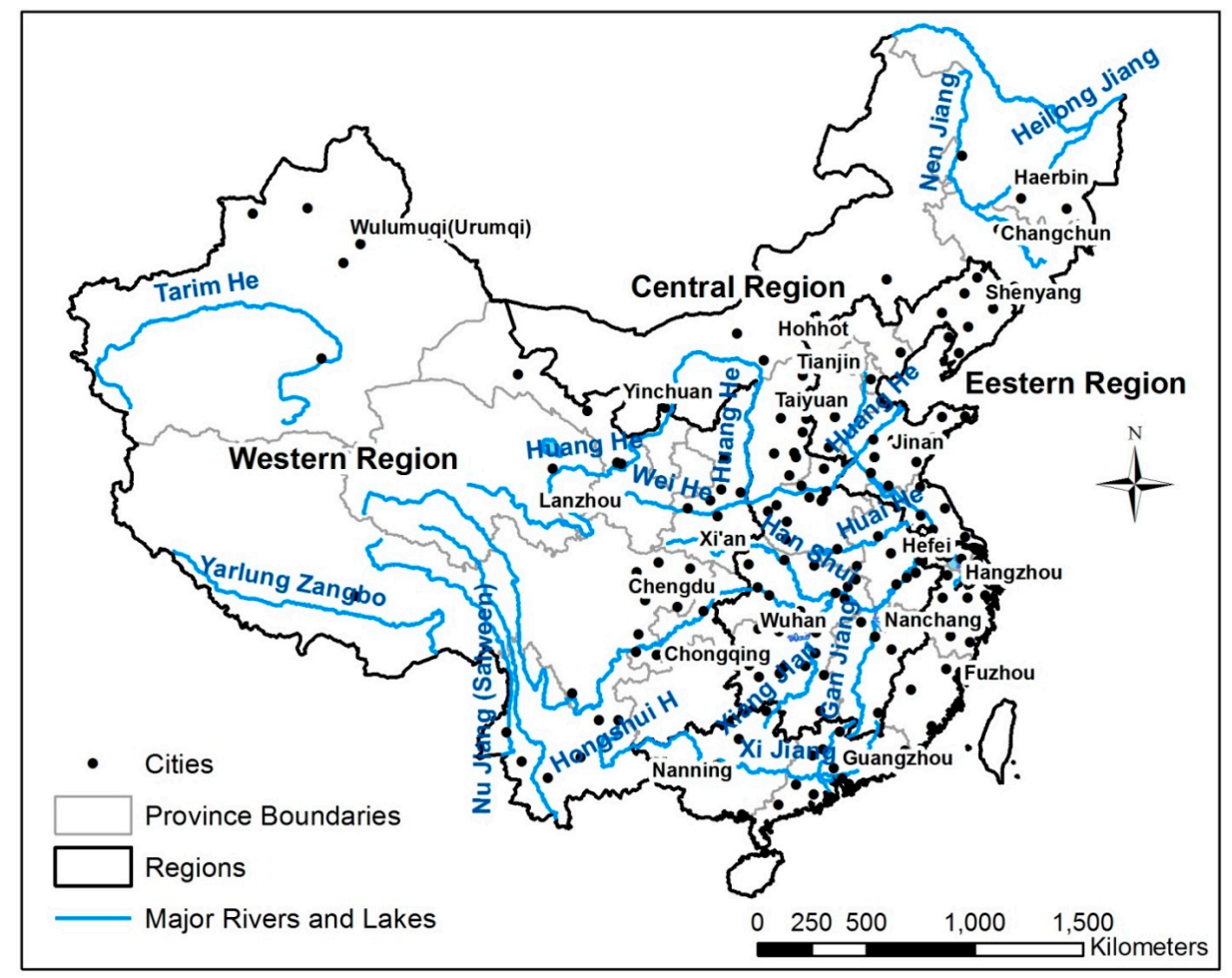

Figure 1. Major water bodies and provincial and prefecture-level cities of China. 


\subsection{Data and Data Sources}

Statistical information used in this study includes water pollution and socioeconomic data (Table 1) as well as GIS shapefiles. GIS allows people to use spatial-temporal data to visualize and analyze patterns and relationships, etc. Water pollution data were downloaded from the Institute of Public \& Environmental Affairs [38]. Social-economic data were obtained from China City Statistical Yearbooks. China Data Center [39] provided GIS shapefiles. Five models were constructed with five different dependent variables (Y), namely the levels of heavy metal pollutants including arsenic (As), cadmium $(\mathrm{Cd})$, chromium $(\mathrm{Cr})$, mercury $(\mathrm{Hg})$, and lead $(\mathrm{Pb})$. The independent variables include socioeconomic factors reflecting urbanization, industrialization, globalization, economic development, as well as physical conditions such as natural resources, hydrological properties of water bodies, and the percentage of green areas of each city.

Table 1. Water pollution data and variables.

\begin{tabular}{|c|c|c|c|}
\hline Classes & & Variables & Indicators \\
\hline Dependent Variable & Heavy me & tal pollutants in 2011 & $\mathrm{As}, \mathrm{Cr}, \mathrm{Hg}, \mathrm{Cd}$ and $\mathrm{Pb}$ \\
\hline \multirow{7}{*}{$\begin{array}{l}\text { Independent } \\
\text { Variables }\end{array}$} & \multirow{4}{*}{$\begin{array}{c}\text { Socioeconomic } \\
\text { Transitions }\end{array}$} & Industrialization & $\begin{array}{l}\text { Gross industrial output of enterprises above } \\
\text { designated size/total industrial output (IND); } \\
\text { Mining and quarrying employers (MQ); Total } \\
\text { passenger traffic (TRA) }\end{array}$ \\
\hline & & Urbanization & Non-agricultural population (URB) \\
\hline & & Globalization & Foreign direct investment capital (GLO) \\
\hline & & Economic Development & GDP per capita (ECO) \\
\hline & \multirow{3}{*}{$\begin{array}{l}\text { Physical } \\
\text { conditions }\end{array}$} & Green land (GRE) & Percentage of green area \\
\hline & & Hydrology (HYD) & Upper, middle and lower reaches \\
\hline & & Natural Resources (NR) & Coal, Chromite, Lead, Petroleum, Pyrite and Zinc \\
\hline
\end{tabular}

\subsection{Methods}

GIS techniques and statistical methods were applied to analyze the spatial patterns of water pollution and examine the impacts of China's socioeconomic development on water pollution. Maps were created for pollution levels of five heavy metals ( $\mathrm{As}, \mathrm{Cd}, \mathrm{Cr}, \mathrm{Hg}$, and $\mathrm{Pb}$ ) from 2004 and 2011 data, respectively. The first year with water pollution available is 2004. Local Indicator of Spatial Association (LISA) was applied to identify local clusters, highlighting areas with high concentrations of heavy metal contamination in both 2004 and 2011 [35,40,41].

Since the 2011 heavy metal pollution data was only available for less than 100 out of the total 334 prefecture-level units, kriging was used to estimate the values for the remaining cities in ArcGIS. Previous studies have proven that kriging has irreplaceable advantages for data estimation because of its high accuracy and low bias [42-44]. For each heavy metal, at least two hundred different combinations of scenarios and parameters were tested, and the best model result was used to create a relevant kriging surface in ArcGIS. The predicted water pollution data of the 174 cities was extracted from the kriging surface and validated by comparing them to the observed values using a paired $t$ test and root-mean-square-error (RMSE) [45]. The optimal estimation data set for each heavy metal was identified based on the results of paired t test ( $p$-value $>0.05$ ) and smallest RMSE. Ordinary least squares (OLS) for each heavy metal was analyzed in EXCEL and ArcGIS. 
Multiple regression models are formulated as follows:

$$
\mathrm{P}=\mathrm{a}+\mathrm{bCON}+\mathrm{cMQ}+\mathrm{dURB}+\mathrm{eIND}+\mathrm{fGLO}+\mathrm{gTRA}+\mathrm{hECO}+\mathrm{iGLO}+\mathrm{jGRE}+\mathrm{kHYD}+\mathrm{INR}
$$

The dependent variable $P$ represents the pollution level of one of the five heavy metals (As, $\mathrm{Cr}, \mathrm{Hg}$, $\mathrm{Cd}$ and $\mathrm{Pb}$ ) in 2011; $a$ is a constant number; and $b, c, d, \ldots, l$ represent coefficient between each heavy metal and the influencing factors.

There were two sets of independent variables (Table 1). The first set of independent variables measures China's socioeconomic transitions, which is constructed by five social aspects: industrialization, decentralization, urbanization, globalization and economic development. Industrialization is represented by three variables: gross industrial output value of enterprises above designated size (IND), transportation (TRA) indicated by the annual number of total transported passengers registered by tickets, as well as the percentage of persons employed in mining and quarrying $(M Q)$, reflecting the intensiveness of mining activities, mineral reserves of a city, and the scale of the mining and quarrying industry. The proportion of non-agricultural population was chosen to represent urbanization (URB). Globalization $(G L O)$ is reflected by actual foreign direct investment value. Economic development $(E C O)$, indicated by GDP per capita, also has influence on environmental conditions. Positive causal relationships are expected between the above independent variables and the pollution levels.

The second set of variables reflects the impact of physical environment on water pollution level. Five types of natural resources with ensured reserves were selected, including metal-rich pyrites and chromite ore, lead and zinc ores, coal, and petroleum. These ensured resources could also intensify environmental pollution including severe water contamination through mining and quarrying activities. Hydrological properties (HYD) of water bodies, indicated by the location of a city within the range of nearby major water bodies, are also influential to city water pollution levels [11]. The cities located at upper, middle, and lower reaches are indicated by 1, 2, and 3, respectively. It was assumed that water was more polluted in the lower reaches near the metal sources than the upper reachers. The percentage of green areas of each city is also an important factor contributing to better water quality [33]. The heavy metal pollution level of 2004 and wastewater treatment rate in each prefecture-level city were chosen as the control variables, which would influence the pollution levels of 2011.

\section{Results and Discussion}

\subsection{Spatial and Temporal Variations of Heavy Metal Water Pollution}

Figures 2-6 exhibit spatiotemporal patterns of five heavy metal water pollution levels for both 2004 and 2011. Except chromium, maximum levels of all the other four metals show drops to some extent from 2004 to 2011, likely reflecting hydrodynamic dispersion (combined effects of diffusion, spreading, and dilution) of contaminants over time as well as more strictly enforced environmental regulations and better compliance at the prefecture-level cities since 2004. Considering the high toxicity of these heavy metals, the Chinese government has established strict pollution control regulations. For example, in 2002, the Chinese government issued environmental quality standards for surface water regulations (GB 3838-2002) to help control water pollution. Therefore, many companies and enterprises introduced more environmentally friendly technologies and equipment afterward.

Table 2 summarizes the top five cities that suffered the highest pollution level of each heavy metal in 2011. Among these 15 heavily polluted cities, 12 are located in central and eastern coastal regions. LISA 
maps show one high arsenic (As) cluster in upstream areas of Yellow River (Baiyin City) in 2004, and three clusters in Yangtze River basin (Chenzhou), Liaohe River watershed (Chifeng), and Pearl River basin (Kunming) in 2011 (Figure 2). Arsenic is often released from production of purified copper and is commonly used for alloys and pesticides [46]. Natural mineral reserves and anthropogenic mining activities are linked to elevated arsenic levels in water reservoirs in China [47-50]. Examples of potential contamination sources are deep groundwater wells (e.g., Chifeng), mining discharges (e.g., Baiyin, Chenzhou, Chongqing, Kunming, and Yichang), utilizing arsenic-rich coal and pyrite, and pesticides used in rural areas.

Table 2. Pollution levels of the top five cities for each heavy metal in 2011.

\begin{tabular}{cccccc}
\hline & As & Cd & Cr & Hg & Pb \\
\hline 1 & Chenzhou & Kunming & Jiaozuo & Zhuzhou & Kunming \\
2 & Kunming & Luoyang & Xiangtan & Nantong & Shaoguan \\
3 & Lhasa & Chenzhou & Nanchang & Chifeng & Chenzhou \\
4 & Jinchang & Shaoguan & Quanzhou & Chenzhou & Luoyang \\
5 & Chifeng & Jinchang & Guangzhou & Shenzhen & Zhuzhou \\
\hline
\end{tabular}

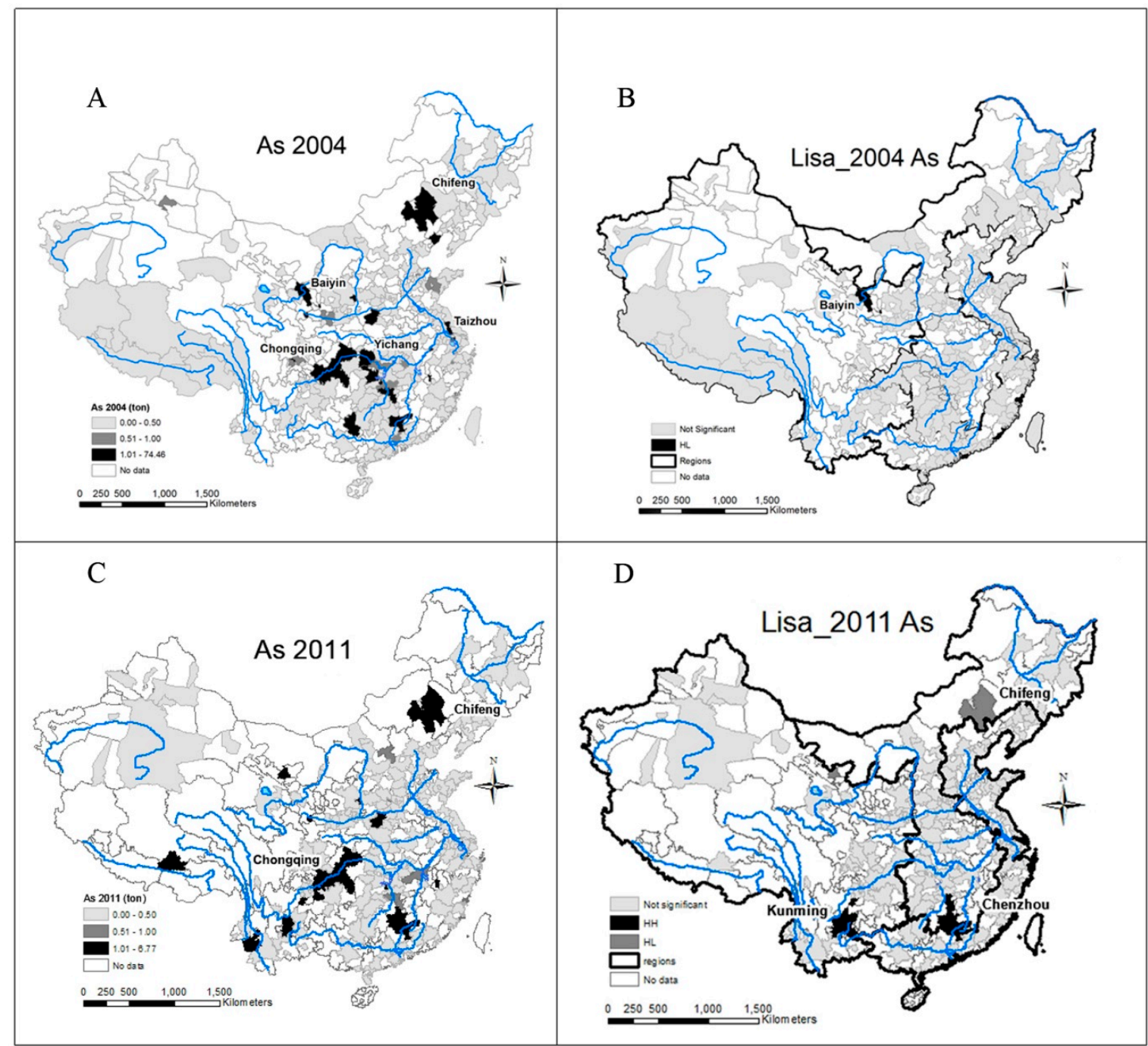

Figure 2. Spatial distribution and LISA maps of Arsenic water pollution: (A) 2004 Arsenic water pollution level; (B) 2011 Arsenic water pollution level; (C) 2004 Arsenic LISA clusters; and (D) 2011 Arsenic LISA clusters. 
High cadmium $(\mathrm{Cd})$ concentrations were detected in the Yangtze River and Yellow River Basins, especially in the central and western regions (Figure 3). LISA maps showed a few clusters of high cadmium pollution level: Baiyin and Huludao in northern China 2004, while Kunming and Chenzhou in southern China 2011. Cadmium is one of the byproducts of zinc production and is typically obtained from cadmium-rich sulfide ore. High concentrations of cadmium are commonly found in zinc and lead ores, phosphate fertilizers [51], and sewage sludge. Higher cadmium concentrations in both 2004 and 2011 were mainly associated with lead and zinc smelting industries, located in such cities as Baiyin, Zhuzhou, Kunming, Shaoguan, and Chenzhou [52,53].

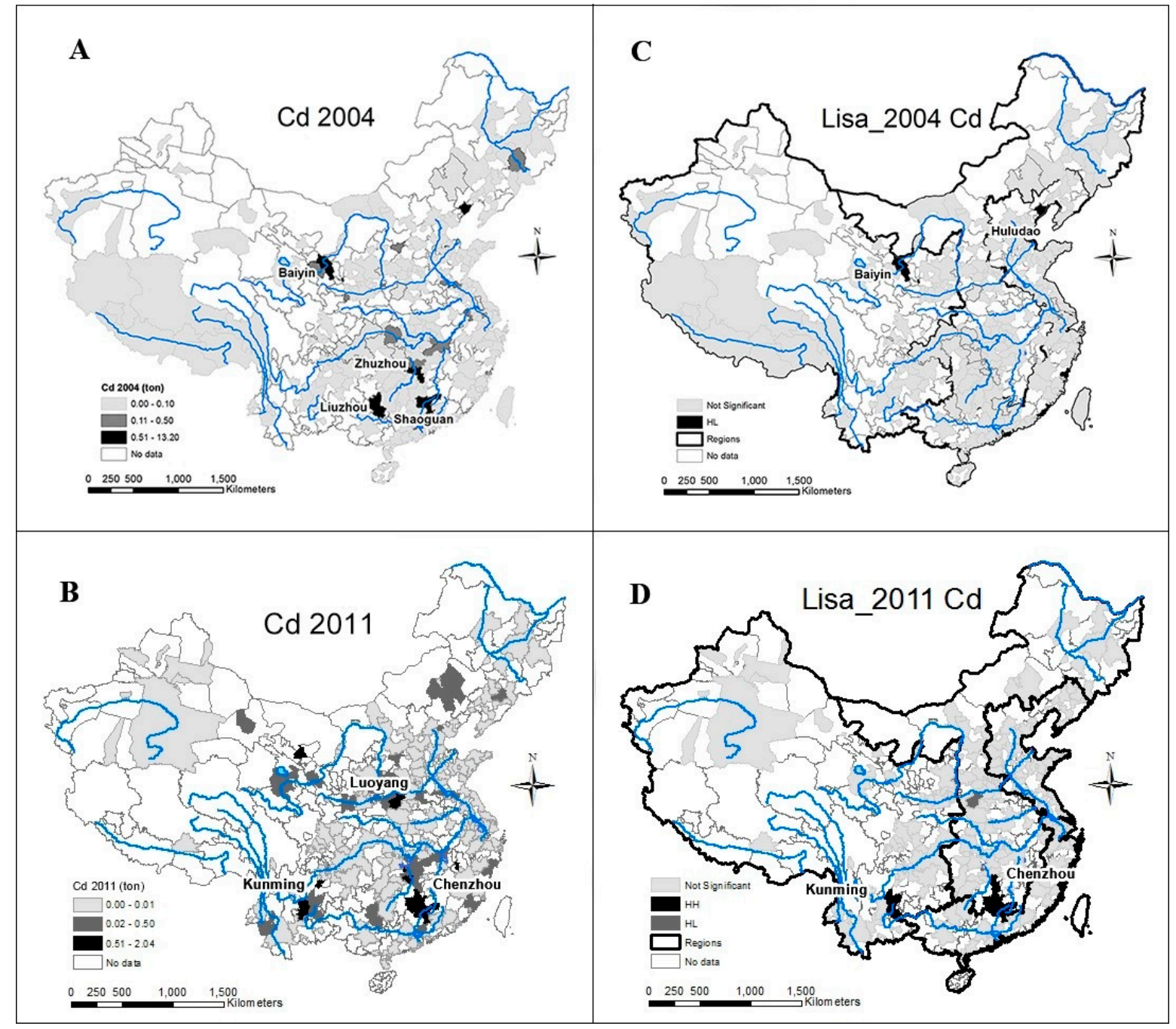

Figure 3. Spatial distribution and LISA maps of Cadmium water pollution: (A) 2004 Cadmium water pollution level; (B) 2011 Cadmium water pollution level; (C) 2004 Cadmium LISA clusters; and (D) 2011 Cadmium LISA clusters.

The chromium $(\mathrm{Cr})$ pollution clusters were widely distributed from coastal areas to the central region, through the Yellow River (Baiyin, Qingdao), Huaihe River, Yangtze River Watershed (Chongqing, Xiangtan), and Pearl River Watershed (Guangzhou) (Figure 4). LISA maps show clusters of high chromium pollution level in Chongqing (2004) and Xiangtan (2011). Sources of chromium pollution include electroplating, medicine production, printing, painting, leather tanning, and dyeing [18,54,55]. For example, Jia et al. (2014) assessed the Chromium pollution at an industrial area of electroplating 
factories in Chongqing. Concentrations of hexavalent Chromium (more toxic form) and total chromium in this wastewater were found to be over 26 and 12 times higher, respectively, at the drain outlets than the national standards. Chromium salts have been manufactured since 1958 in over 70 factories in China, including Guangzhou, Chongqing, Qingdao, Xining, and Shanghai [55]. These cities all have high population densities, and produced over 600 million tons of chromium slag. Chromium slag contamination from the slag stacks causes widespread chromium pollution, consistent with the results revealed in the maps from this research.

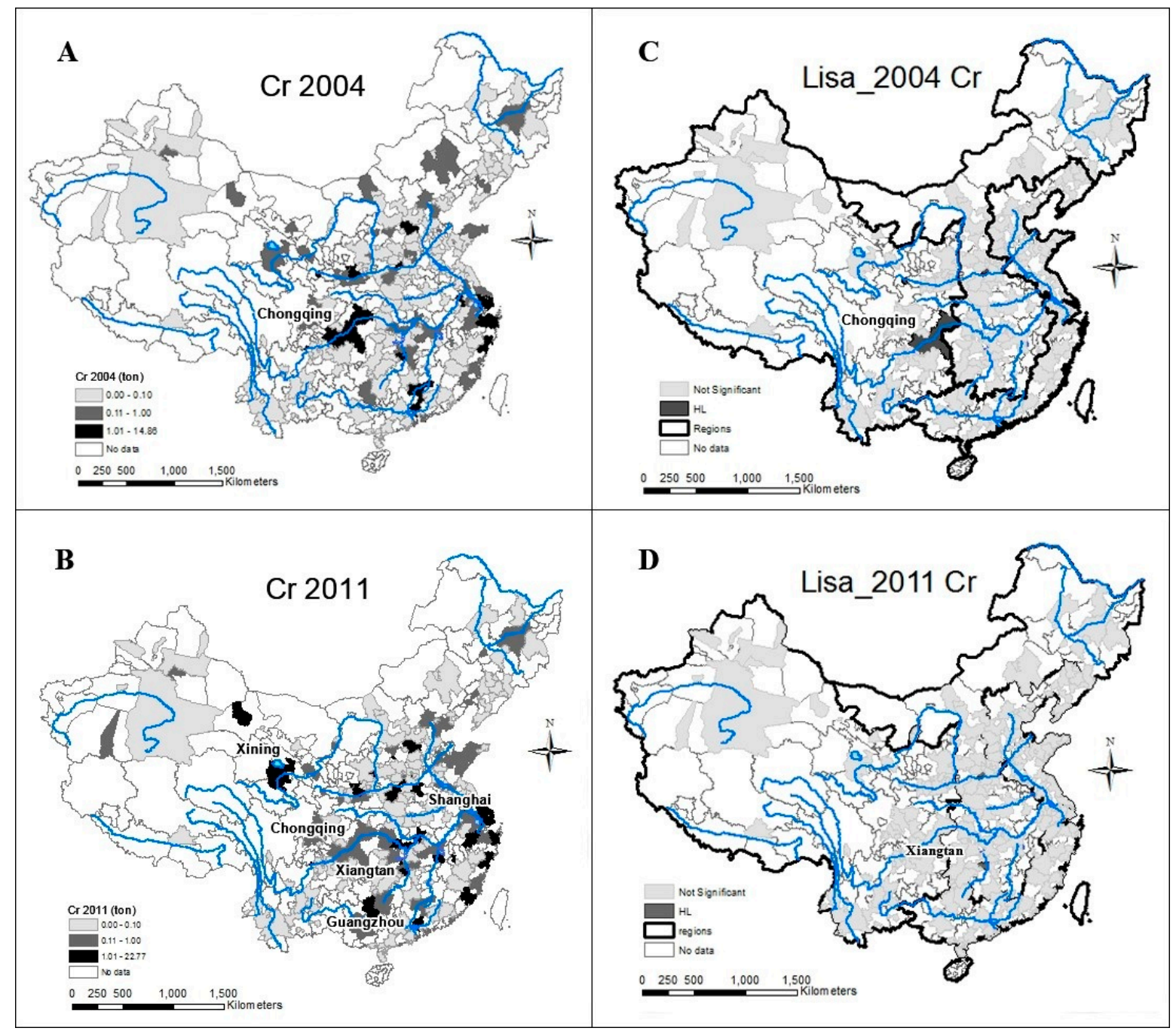

Figure 4. Spatial distribution and LISA maps of Chromium water pollution: (A) 2004 Chromium water pollution level; (B) 2011 Chromium water pollution level; (C) 2004 Chromium LISA clusters; and (D) 2011 Chromium LISA clusters.

Cities with high mercury $(\mathrm{Hg})$ pollution levels are distributed throughout northeast and southeast parts of China, mainly in the Liaohe River (Chifeng) and Yangtze River watersheds (Shaoguan, Zhuzhou) (Figure 5). LISA maps show clusters of high chromium pollution level in Shaoguan (2004, 2011) and Chifeng (2011). Mining (gold and mercury), chemical industry and coal combustion are important anthropogenic sources of $\mathrm{Hg}$ pollution in China [56]. Mercury may contaminate the environment through burning fossil fuel, i.e., coal and petroleum. For example, coal combustion was responsible for the high mercury levels in Chifeng [57] and Chongqing [58]. Smelting and chemical plants lead to high 
mercury pollution in Zhuzhou, Hunan Province. Shaoguan's elevated mercury levels, highlighted from the LISA maps, were related to both Shaoguan Smelting Plant and Dabaoshan Mining Co., Ltd. [59].

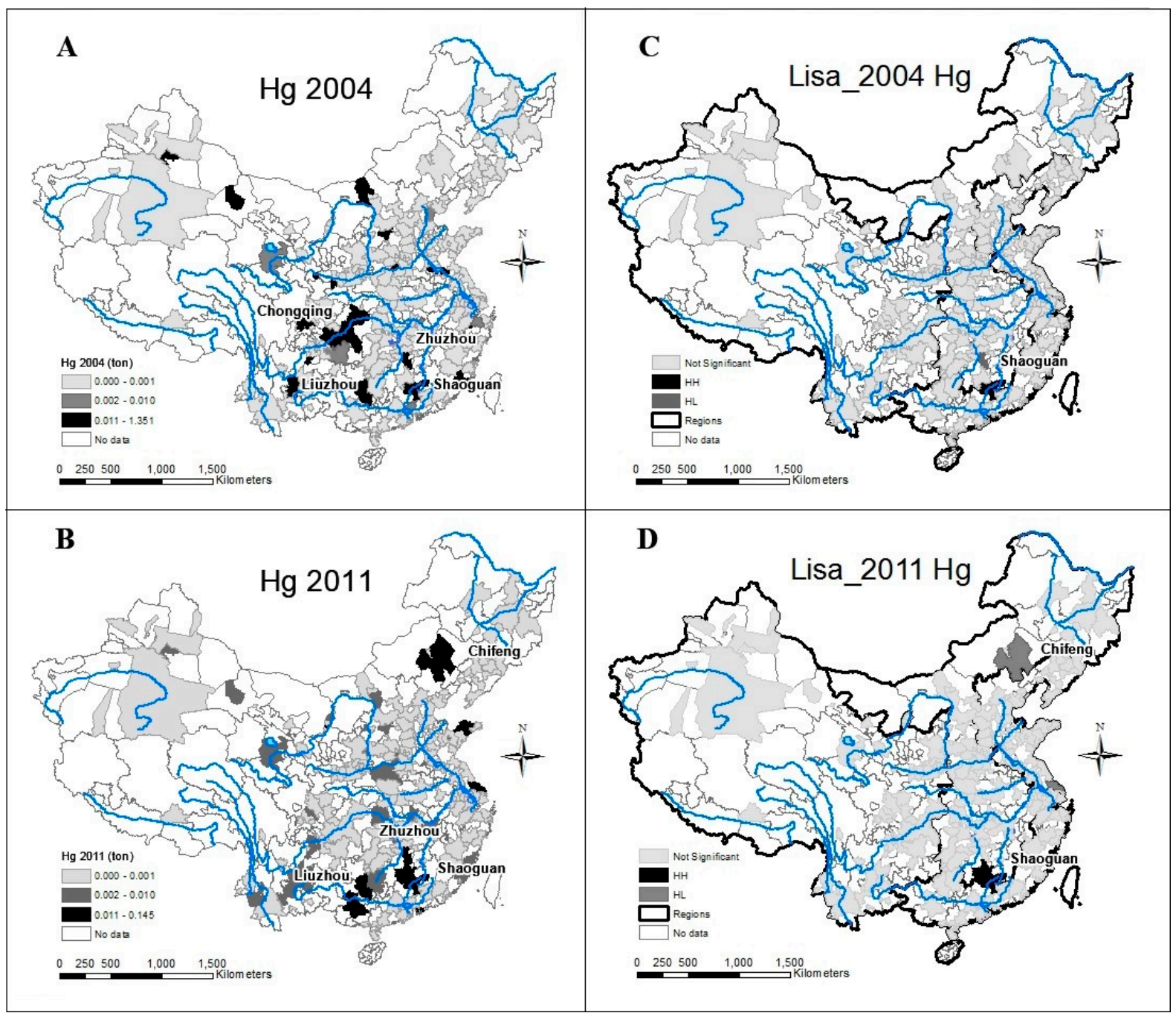

Figure 5. Spatial distribution and LISA maps of Mercury water pollution: (A) 2004 Mercury water pollution level; (B) 2011 Mercury water pollution level; (C) 2004 Mercury LISA clusters; and (D) 2011 Mercury LISA clusters.

Cities with high lead $(\mathrm{Pb})$ concentration were found upstream of the Yellow River (Baiyin, Chifeng), Yangtze River drainage areas (Suzhou, Zhuzhou), and Pearl River basin (Shaoguan) (Figure 6). LISA maps show several clusters of high cadmium pollution level: Baiyin and Zhuzhou in 2004, and Kunming, Chenzhou, and Shaoguan in 2011. Major sources of lead pollution in China are lead/zinc mining, smelting activities, and lead-acid battery industries [60,61]. For example, Yunnan Province in Southwestern China is rich in mineral resources, especially lead-zinc deposits. Kunming, the capital city of Yunnan, is one of the most important lead production industrial bases in China. Other lead and zinc smelting industries responsible for high lead pollution are mainly located in Baiyin, Zhuzhou, Shaoguan, and Chenzhou $[52,53,59,60]$. One report indicated that blood lead levels of some children in Chifeng were as high as $162 \mathrm{ug} / \mathrm{L}$; much higher than the upper threshold level of $99 \mathrm{ug} / \mathrm{L}$ [62]. This health impact was linked to the emissions from the Jinjian Copper Smelting Plant, established in 1990. Lead is commonly 
used in battery production. Highest producing lead-acid battery industries, mainly located in Jiangsu, Zhejiang and Guangdong provinces, contributed to higher lead pollution levels in those areas.

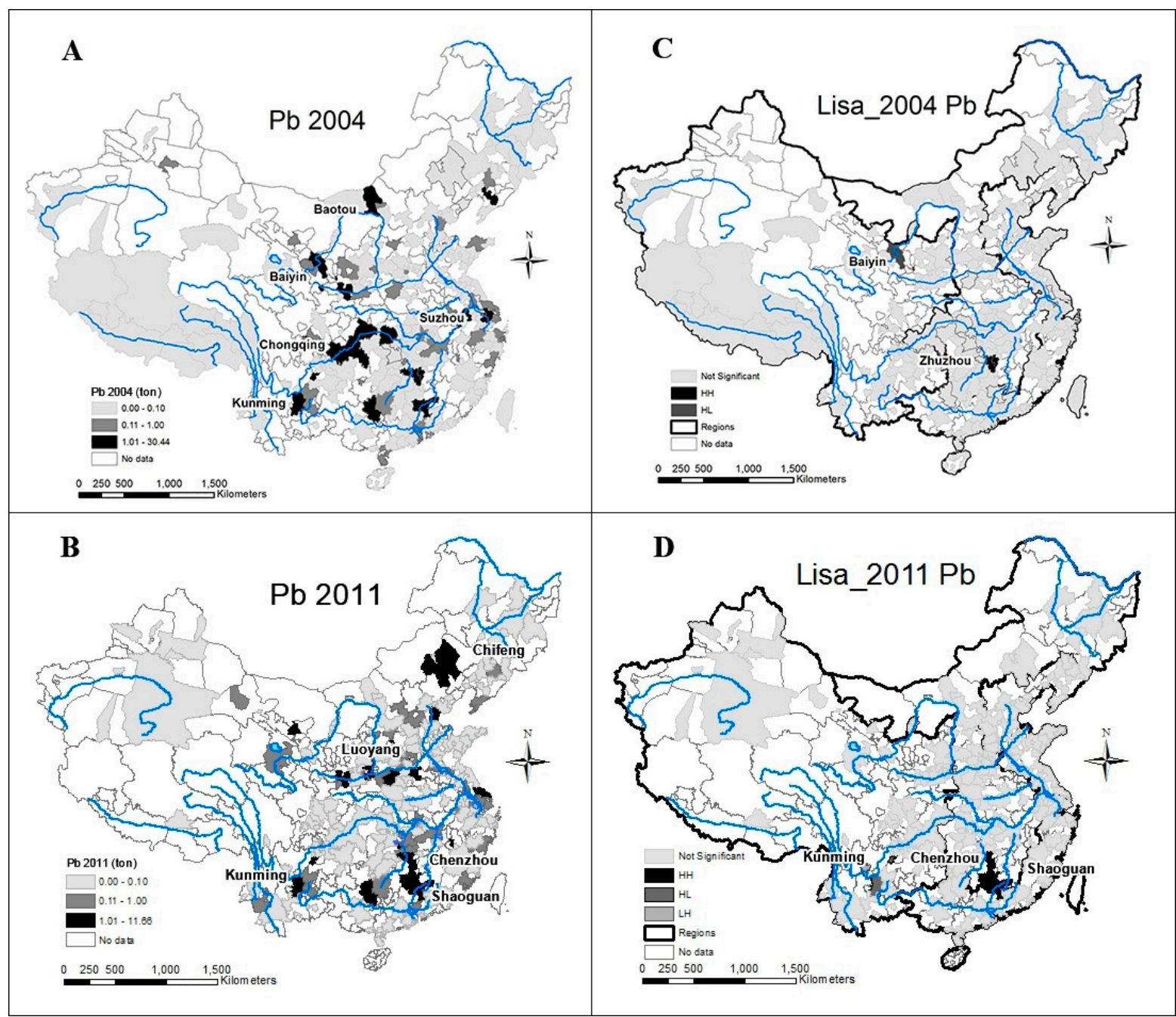

Figure 6. Spatial distribution and LISA maps of Lead water pollution: (A) 2004 Lead water pollution level; (B) 2011 Lead water pollution level; (C) 2004 Lead LISA clusters; and (D) 2011 Lead LISA clusters.

\subsection{Socioeconomic Transitions, Physical Conditions, and Heavy Metal Water Pollution}

\subsubsection{Heavy Metal Water Pollution Estimation Using Kriging and Model Validation}

Because heavy metal water pollution data is not available for all cities in this research, kriging models were used to predict water pollution levels for 160 cities in 2011. Different scenarios and parameters were modeled for kriging and semivariogram methods, including the search radius, number of points, and maximum distance for each heavy metal (Figure 7). The kriging surfaces were created, and predicted values were extracted via ArcGIS (Figure 8). Results showed optimal cell size and search radius, using ordinary kriging methods with a spherical semivariogram, to achieve the best estimation performance. RMSE values were calculated in Excel. Values closest to 0 indicate the best prediction. After extensive calibration, the optimal scenario was found for each heavy metal model based on the smallest RMSE values. A paired t-test was further applied to compare predicted and observed values. All $p$-values (two tailed) 
were larger than $0.05(0.89-0.98)$, indicating that the model calibration was reliable and that there were no differences between observed and predicted values at the five percent significance level. The optimal scenario RMSE and t-test results are summarized in Table 3. Based on the kriging estimation and model validation, the fittest and most reliable pollution predicted data was then used to construct OLS models.
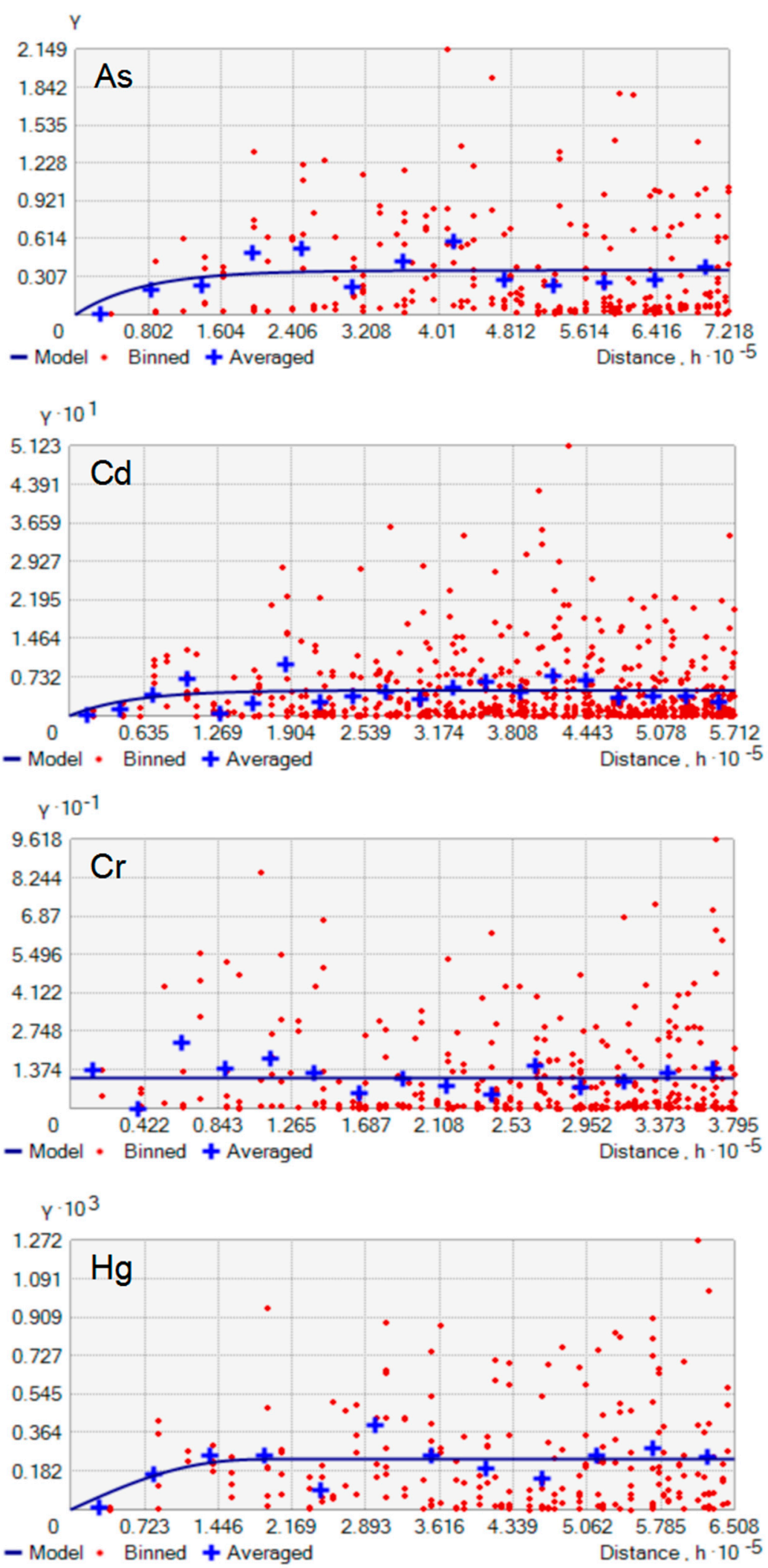

Figure 7. Cont. 


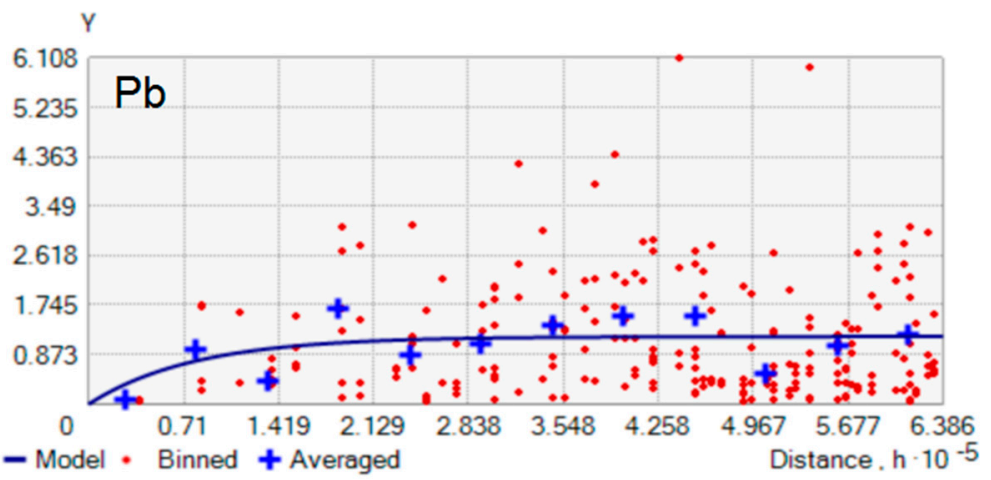

Figure 7. Semivariograms for five heavy metals.

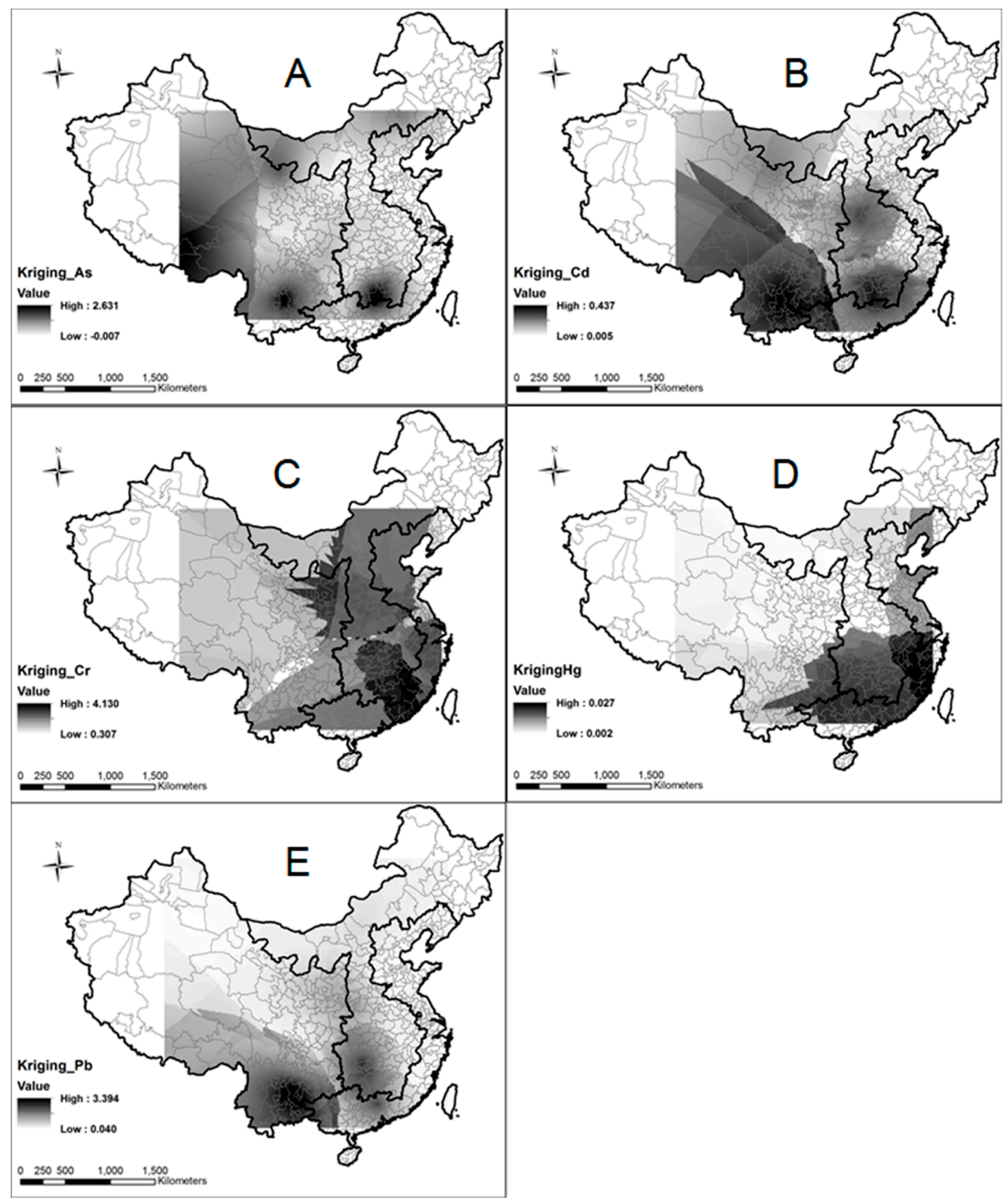

Figure 8. Kriging surfaces for five heavy metals: (A) $\mathrm{As}(\mathbf{B}) \mathrm{Cd}(\mathbf{C}) \mathrm{Cr}(\mathbf{D}) \mathrm{Hg}$ and (E) $\mathrm{Pb}$. 
Table 3. Parameters and validation results of optimal kriging models.

\begin{tabular}{lccccc}
\hline \multicolumn{1}{c}{ Heavy Metals } & As & $\mathbf{C d}$ & $\mathbf{C r}$ & $\mathbf{H g}$ & $\mathbf{P b}$ \\
\hline Kriging method & Universal & Ordinary & Ordinary & Universal & Universal \\
Kernel function & Exponential & Exponential & Exponential & Exponential & Exponential \\
Lag size & 55,523 & 28,562 & 25,300 & 54,236 & 53,220 \\
Number lags & 13 & 20 & 15 & 12 & 12 \\
Order of trend removal & Constant & Constant & Second & Second & Constant \\
Anisotropy & False & False & False & False & False \\
Semivariogram model & Exponential & Exponential & Spherical & Pentaspherical & Exponential \\
Number of observed points & 77 & 58 & 97 & 39 & 87 \\
Mean error & 0.003 & -0.002 & -0.002 & -0.033 & -0.004 \\
RMSE & 0.829 & 0.235 & 2.828 & 0.968 & 1.222 \\
Average standard error & 0.551 & 0.212 & 3.327 & 0.015 & 0.994 \\
$p$-value & 0.94 & 0.97 & 0.92 & 0.89 & 0.98 \\
\hline
\end{tabular}

\subsubsection{OLS Regression Results}

Table 4 presents the results of the multiple regression models (OLS). Multiple regression models of arsenic (As), cadmium $(\mathrm{Cd})$, chromium $(\mathrm{Cr})$, mercury $(\mathrm{Hg})$, and lead $(\mathrm{Pb})$ are all significant at the one percent significance level. Heavy metal pollution connects tightly with human activities, mineral deposits and metallic characters and applications.

The model used for As in this study explained 30 percent of the variance through eleven independent variables $\left(R^{2}=0.3\right)$ (Table 4$)$, in which industrialization (IND), urbanization (URB), natural resource indicated by pyrite ores (NR) considering the high arsenic level in pyrite sulfide mineral, waste water treatment rate, and As pollution levels in 2004 were significant. Urbanization and wastewater treatment rate had negative coefficients, indicating that prefecture-level cities with better wastewater treatment had lower arsenic pollution level. Pesticide is one of the most common utilization of arsenic in rural areas [46]. The statistic results concurred that arsenic pollution levels are relatively lower in more urbanized prefectures. Pyrite reserves, industrialization, and As levels in 2004 had positive correlation with As pollution levels in 2011. Results show industrialization, in terms of the gross industrial output value of enterprises above designated size, has aggravated the arsenic water pollution the most. Natural mining resources and geologic features also have profound influences on heavy metal pollution. For example, naturally-derived arsenic in alluvial sediments is the culprit for the water pollution in India, Bangladesh, and the western part of China; especially in Tibet [14]. Sulfide minerals are only stable under reducing geochemical conditions in subsurface. Through mining and excavating, sulfide minerals can be weathered and release arsenic under oxidized conditions. Great quantity of discharged wastewater accumulated from 2004 could also persist in the environment and result in high heavy metal (such as arsenic, cadmium, and lead) water pollution level in 2011. 
Table 4. Multiple regressions on the pollution level of each of the five heavy metals (As, $\mathrm{Cr}, \mathrm{Hg}, \mathrm{Cd}$ and $\mathrm{Pb}$ ) in 2011.

\begin{tabular}{|c|c|c|c|c|c|c|}
\hline & Independent Variables & $\begin{array}{c}\text { Coefficient } \\
\text { (As) }\end{array}$ & $\begin{array}{c}\text { Coefficient } \\
\text { (Cd) }\end{array}$ & $\begin{array}{c}\text { Coefficient } \\
\text { (Cr) }\end{array}$ & $\begin{array}{c}\text { Coefficient } \\
(\mathrm{Hg}) \\
\end{array}$ & $\begin{array}{c}\text { Coefficient } \\
(\mathrm{Pb})\end{array}$ \\
\hline \multirow{3}{*}{$\begin{array}{c}\text { Control } \\
\text { Variables }\end{array}$} & Intercept & $1.501 * * *$ & $0.216 * * *$ & $2.253 * * *$ & $0.010 *$ & $0.984 * *$ \\
\hline & Treatment Rate & $-0.013 * * *$ & -0.001 & -0.004 & 0.000 & -0.004 \\
\hline & Heavy metals in 2004 & $0.053 * *$ & $0.050 * *$ & 0.033 & 0.006 & $0.056 * * *$ \\
\hline \multirow{6}{*}{$\begin{array}{c}\text { Socioeconomic } \\
\text { Transitions }\end{array}$} & Mining \& Quarrying (MQ) & 0.017 & 0.003 & -0.013 & -0.000 & 0.016 \\
\hline & Enterprises (IND) & $0.152 * * *$ & 0.007 & -0.125 & -0.001 & $0.132 * *$ \\
\hline & Transportation (TRA) & -0.000 & $0.000 *$ & -0.000 & 0.000 & -0.000 \\
\hline & Urbanization (URB) & $-0.550 * *$ & $-0.103 * *$ & -0.112 & -0.003 & -0.397 \\
\hline & Globalization (GLO) & 0.000 & -0.000 & -0.000 & -0.000 & 0.000 \\
\hline & Economy (ECO) & 0.000 & $-0.000 *$ & 0.000 & 0.000 & -0.000 \\
\hline \multirow{5}{*}{$\begin{array}{l}\text { Physical } \\
\text { conditions }\end{array}$} & Natural resources (NR) & $0.000 * *$ & $0.000 * * *$ & $-0.030 * * *$ & $-0.000 * * *$ & $0.003 * * *$ \\
\hline & Green coverage rate (GRE) & 0.031 & 0.006 & 0.009 & 0.001 & 0.062 \\
\hline & Hydrology (HYD) & -0.037 & 0.007 & -0.063 & 0.000 & -0.067 \\
\hline & Significance F & $0.00 * * *$ & $0.00 * * *$ & $0.00 * * *$ & $0.00 * * *$ & $0.00 * * *$ \\
\hline & $\mathrm{R}$-square & 0.30 & 0.34 & 0.17 & 0.29 & 0.30 \\
\hline
\end{tabular}

Note: $* p$-value is significant at $10 \%$ significance level; ** $p$-value is significant at $5 \%$ significance level; $* * * p$-value is significant at $1 \%$ significance level.

For Cd pollution, about 34 percent of the variance was explained through eleven independent variables $\left(R^{2}=0.34\right)$ (Table 4). Zinc reserves value was chosen to represent the natural resource influence, because most zinc ores contain minor amount of cadmium element. Five variables are significant to Cd pollution level: urbanization (URB), transportation (TRA), economic development (ECO), natural mineral resource (NR), and Cd pollution level in 2004. Urbanization and economic development (ECO) corresponded with $\mathrm{Cd}$ pollution level negatively. For example, as an agricultural economy dominated province, Hunan alone discharged 50 percent of the national cadmium wastewater. In 2013, large quantities of cadmium-contaminated rice from Hunan were detected in Guangdong Province, causing great public concerns about food safety. Considering the high toxicity of cadmium, the usage and production of cadmium in smelting industries have decreased and strictly controlled by governments' regulations, particularly in urban and well-developed areas $[63,64]$. Transportation development has also worsened Cd pollution because busy traffic in areas with high road density increases vehicle emissions and contamination accumulation [65].

OLS models showed 17 percent and 29 percent, respectively, of $\mathrm{Cr}\left(R^{2}=0.17\right)$ and $\mathrm{Hg}\left(R^{2}=0.29\right)$ levels changes. Only one variable was significant for both $\mathrm{Cr}$ and $\mathrm{Hg}$ model, which is natural mineral reserve (NR). Petroleum and coal reserves were chosen to represent the influence from natural resources for the $\mathrm{Hg}$ model. Mercury resources in China are mainly concentrated in the south. Chromite ores were chosen as the natural resource variable for $\mathrm{Cr}$ regression model. According to the China Statistical Yearbook on Environment, ensured chromite ores are located mainly in Tibet, Inner Mongolia, Xinjiang, etc. This variable was negatively associated with both $\mathrm{Cr}$ and $\mathrm{Hg}$ levels. This may because of the strict regulation about mining activity from the government. For example, Chinese government signed the Minamata Convention Treaty and followed the regulations to reduce emissions and usage of mercury [66]. 
The OLS model accounted for 30 percent of lead contamination variations in $2011\left(\mathrm{R}^{2}=0.3\right)$. The lead regression model was very sensitive to three variables: industrialization (IND), lead reserves (NR), and lead pollution level in 2004. Industrialization has intensified the lead pollution problem in China. Lead pollution in China is commonly caused by lead/zinc mining, smelting activities, and lead-acid battery industries [60,61]. For example, China, specifically in Guangdong (i.e., Foxconn), is the largest battery producer for Apple Company [67]. Also, many enterprises increase their output values and profit through budget saving from water pollution treatment and control facilities [68]. In addition, abundant lead reserves are widely distributed over the country, especially high in Inner Mongolia, Yunnan, and Guangdong. The geographic proximity to natural reserves leads to industrialization booms, which bring about pollution problems. As the control variable, the $2004 \mathrm{~Pb}$ pollution level is positively associated with the 2011 level.

In summary, both natural mineral resources and human activities play significant roles in explaining the spatial variation of China's heavy metal water pollution. For instance, Chenzhou and Changde (in Hunan Province, Southern China) are classified as high level As pollution cities, shown in the 2011 LISA map (Figure 2D). Chenzhou has abundant tungsten and bismuth ores. Hundreds of minerals have been ascertained in Changde, especially rich realgar (an arsenic sulfide mineral) ore, which is one of the main resources of arsenic production [69]. Luoyang, a city of Henan Province in central China, is a populated city with the largest molybdenum reserve in the country. Not surprisingly, it had very high chromium and lead pollution levels (Table 2 and Figure 3B,D). These highly polluted industrial based cities all have many different types of abundant mineral resources and heavy mining activities. Geographic locations (i.e., coastal areas vs. locally enclosed water bodies) and hydrologic characteristics play an important role in diagnosing pollution levels [70]. Taizhou, Wenzhou, Suzhou and surrounding coastal areas had relatively high chromium pollution concentrations (Figure 4A,B). These seriously populated areas are heavily industrialized and urbanized with highly developed economies.

\section{Conclusions}

This research contributes to the literature by investigating heavy metal water pollution conditions in Mainland China from a spatiotemporal perspective, while examining the influences of socioeconomic activities and natural conditions on water pollution. The results illustrate the decrease of pollution levels from 2004 to 2011. Except cadmium (Cd), the individual pollution levels of the other four heavy metals, arsenic (As), chromium $(\mathrm{Cr})$, mercury $(\mathrm{Hg})$, and lead $(\mathrm{Pb})$, declined to some extent during the study period. Dispersion of contaminants and strict government pollution control may have led to the decline of pollution levels of these metals since 2004. This result concurs with the findings of Wang et al. [17]; that the heavy metal pollution has been partly relieved in China since the mid-1990s. The analytical results show that the highly polluted prefecture-level cities are mainly concentrated in the central and eastern coastal regions, although the distributions of individual metals exhibit various patterns. This study also reveals that high metal pollution levels are associated with both anthropogenic activities and physical environments, especially due to the prosperity of industrialization and the abundance of mineral resources. Economic development and urbanization also play important roles in explaining water pollution problems. Most of the heavily polluted prefecture-level cities are traditional industrial centers 
and are highly economically developed with large urban populations. This conclusion matches consistently with findings of previous studies on Tibet, Tianjin, Hunan, Heilongjiang, etc. [10,11,20,34,71].

This research has both scientific and policy implications by providing informative knowledge on China's water pollution pattern and helping researchers better understand the complex underlying risk factors. The research findings will provide valuable references for the governmental agencies to initiate and adjust relevant policies for protecting water resources as well as improving the health of citizens. Prefecture-level cities, such as Kunming, Zhuzhou, Chenzhou, Shaoguan, Chongqing, especially need more pollution control efforts for the sake of citizen's wellbeing and local sustainable development. However, bias may exist in raw data due to deliberate false reports of lower discharged pollutant values by enterprises in order to avoid penalties. In addition, other influential forces such as water quality regulations of local government forces, migration, and landscapes, etc., were not taken into consideration, but may also contribute to heavy metal water pollution. In a future study, we are planning to expand the investigation by analyzing watershed-level and regional-scale data and incorporating more risk factors to further our understanding on China's water pollution.

\section{Acknowledgments}

We would like to acknowledge the funding of the National Natural Science Foundation of China (41430637; 41329001).

\section{Author Contributions}

Huixuan Li conducted GIS and statistical analysis and wrote the manuscript; Yingru Li designed the analytical framework of this study and provided methodological advices as well as made major revisions of the manuscript; Ming-Kuo Lee provided natural resource and hydrological analyses as well as revised the manuscript; Zhongwei Liu conducted statistical analysis and made revisions of the manuscript; and Changhong Miao contributed to this research by providing financial support, collecting and processing data, and coordinating the research team.

\section{Conflicts of Interest}

The authors declare no conflict of interest.

\section{References}

1. World Resource Institute. 2007. Available online: http://www.wri.org/publication/wri-annualreport-2006-2007 (accessed on 21 April 2014).

2. Bao, L.-J.; Maruya, K.A.; Snyder, S.A.; Zeng, E.Y. China's water pollution by persistent organic pollutants. Environ. Pollut. 2012, 163, 100-108.

3. Hu, Y.; Cheng, H. Water pollution during China's industrial transition. Environ. Dev. 2013, 8, $57-73$.

4. Ministry of Water Resources of China (MWR). China Country Report on Sustainable Development-Water Resources; Ministry of Water Resources, People's Republic of China: Beijing, China, 2003. 
5. Ministry of Water Resources of China (MWR). China Water Resources Bulletin; Ministry of Water Resources, People's Republic of China: Beijing, China, 2012.

6. Liu, J.; Diamond, J. China's environment in a globalizing world. Nature 2005, 435, 1179-1186.

7. Carr, R.; Zhang, C.; Moles, N.; Harder, M. Identification and mapping of heavy metal pollution in soils of a sports ground in Galway City, Ireland, using a portable XRF analyser and GIS. Environ. Geochem. Health 2008, 30, 45-52.

8. Liu, L. Made in China: cancer villages. Environ. Sci. Policy Sustain. Dev. 2010, 52, 8-21.

9. Watts, J. Lead poisoning cases spark riots in China. Lancet 2009, doi:10.1016/S01406736(09)61612-3.

10. Hu, H.; Jin, Q.; Kavan, P. A study of heavy metal pollution in China: Current status, pollution-control policies and countermeasures. Sustainability 2014, 6, 5820-5838.

11. Zhai, L.; Liao, X.; Chen, T.; Yan, X.; Xie, H.; Wu, B.; Wang, L. Regional assessment of cadmium pollution in agricultural lands and the potential health risk related to intensive mining activities: A case study in Chenzhou City, China. J. Environ. Sci. 2008, 20, 696-703.

12. Ebenstein, A. The consequences of industrialization: Evidence from water pollution and digestive cancers in China. Rev. Econ. Stat. 2012, 94, 186-201.

13. Lee, C.-C.; Chiu, Y.-B.; Sun, C.-H. The environmental Kuznets curve hypothesis for water pollution: Do regions matter? Energy Policy 2010, 38, 12-23.

14. Schwarzenbach, R.P.; Egli, T.; Hofstetter, T.B.; von Gunten, U.; Wehrli, B. Global water pollution and human health. Ann. Rev. Environ. Resour. 2010, 35, 109-136.

15. Jiang, J.; Wang, P.; Lung, W.; Guo, L.; Li, M. A GIS-based generic real-time risk assessment framework and decision tools for chemical spills in the river basin. J. Hazard. Mater. 2012, 227, 280-291.

16. Sheng, J.; Wang, X.; Gong, P.; Tian, L.; Yao, T. Heavy metals of the Tibetan top soils. Environ. Sci. Pollut. Res. 2012, 19, 3362-3370.

17. Wang, S.-L.; Xu, X.-R.; Sun, Y.-X.; Liu, J.-L.; Li, H.-B. Heavy metal pollution in coastal areas of South China: A review. Mar. Pollut. Bull. 2013, 76, 7-15.

18. Jia, Y.; Bai, Q.; Xiao, H. Investigation of the status of chromium pollution at an electroplating industrial area in Chongqing. Modern Prev. Med. 2014, 6, 978-980.

19. Zhong, L.; Liu, L.; Yang, J. Characterization of heavy metal pollution in the paddy soils of Xiangyin County, Dongting lake drainage basin, central south China. Environ. Earth Sci. 2012, 67, 2261-2268.

20. Meng, W.; Qin, Y.; Zheng, B.; Zhang, L. Heavy metal pollution in Tianjin Bohai bay, China. J. Environ. Sci. 2008, 20, 814-819.

21. Yang, T.; Liu, J. Health Risk Assessment and Spatial Distribution Characteristic on Heavy Metals Pollution of Haihe River Basin. J. Environ. Anal. Toxicol. 2012, 2, 152.

22. Huang, F.; Wang, X.; Lou, L.; Zhou, Z.; Wu, J. Spatial variation and source apportionment of water pollution in Qiantang River (China) using statistical techniques. Water Res. 2010, 44, 1562-1572.

23. Madkour, H.A. Distribution and relationships of heavy metals in the giant clam (Tridacna maxima) and associated sediments from different sites in the Egyptian Red Sea coast. Egypt. J. Aqua. Res.

2005, 31, 45-59. 
24. Wei, B.; Yang, L. A review of heavy metal contaminations in urban soils, urban road dusts and agricultural soils from China. Microch. J. 2010, 94, 99-107.

25. Li, Y.; Wei, D.Y. The spatial-temporal hierarchy of regional inequality of China. Appl. Geogr. 2010, 30, 303-316.

26. Wang, M.M.; Webber, B.F; Barnett, J. Rural industries and water pollution in China. J. Environ. Manage. 2008, 86, 648-659.

27. DeCatanzaro, R.; Cvetkovic, M.; Chow-Fraser, P. The relative importance of road density and physical watershed features in determining coastal marsh water quality in Georgian Bay. Environ. Manage. 2009, 44, 456-467.

28. Feng, J.; Zhao, J.; Bian, X.; Zhang, W. Spatial distribution and controlling factors of heavy metals contents in paddy soil and crop grains of rice-wheat cropping system along highway in East China. Environ. Geochem. Health 2012, 34, 605-614.

29. He, C.; Huang, Z.; Ye, X. Spatial heterogeneity of economic development and industrial pollution in urban China. Stoch. Environ. Res. Risk Assess. 2014, 28, 767-781.

30. Christmann, P.; Taylor, G. Globalization and the environment: Determinants of firm self-regulation in China. J. Int. Bus. Stud. 2001, 32, 439-458.

31. He, C.; Pan, F.; Yan, Y. Is economic transition harmful to China's urban environment? Evidence from industrial air pollution in Chinese cities. Urban. Stud. 2012, 49, 1767-1790.

32. Alexander, R.B.; Boyer, E.W.; Smith, R.A.; Schwarz, G.E.; Moore, R.B. The role of headwater streams in downstream water quality. JAWRA J. Am. Water Resour. Assoc. 2007, 43, 41-59.

33. Liu, Z.; Li, Y.; Li, Z. Surface water quality and land use in Wisconsin, USA-A GIS approach. J. Integr. Environ. Sci. 2009, 6, 69-89.

34. Li, Z.; Ma, Z.; van der Kuijp, T.J.; Yuan, Z.; Huang, L. A review of soil heavy metal pollution from mines in China: Pollution and health risk assessment. Sci. Total Environ. 2014, 468, 843-853.

35. Li, Y.; Wei, D.Y. A spatial-temporal analysis of health care and mortality inequalities in China. Eurasian Geogr. Econ. 2010, 51, 767-787.

36. Dhakal, S. Urban energy use and carbon emissions from cities in China and policy implications. Energy Policy 2009, 37, 4208-4219.

37. China Statistical Yearbook; Beijing, China, 2005.

38. Institute of Public \& Environmental Affairs. Available online: http://www.ipe.org.cn/pollution/ status.aspx (accessed on 21 May 2013).

39. China Data Center. Available online: http://chinadatacenter.org/ (accessed on 21 May 2013).

40. Anselin, L. Local indicators of spatial association-LISA. Geogr. Anal. 1995, 27, 93-115.

41. Fotheringham, A.S.; Brunsdon, C.; Charlton, M. Geographically Weighted Regression: The Analysis of Spatially Varying Relationships; John Wiley \& Sons: West Sussex, UK, 2003.

42. Li, X.; Cheng, G.; Lu, L. Spatial analysis of air temperature in the Qinghai-Tibet Plateau. Arct. Antarct. Alp. Res. 2005, 37, 246-252.

43. Yang, J.S.; Wang, Y.Q.; August, P.V. Estimation of land surface temperature using spatial interpolation and satellite-derived surface emissivity. J. Environ. Inform. 2004, 4, 37-44.

44. Simasuwannarong, B.; Satapanajaru, T.; Khuntong, S.; Pengthamkeerati, P. Spatial distribution and risk assessment of $\mathrm{As}, \mathrm{Cd}, \mathrm{Cu}, \mathrm{Pb}$, and $\mathrm{Zn}$ in topsoil at Rayong Province, Thailand. Water Air Soil Pollut. 2012, 223, 1931-1943. 
45. Wu, T.; Li, Y. Spatial interpolation of temperature in the United States using residual kriging. Appl. Geogr. 2013, 44, 112-120.

46. United States Geological Survey. Arsenic. Available online: http://minerals.er.usgs.gov/minerals/pubs/ commodity/arsenic/mcs-2008-arsen.pdf (accessed on 7 July 2014).

47. Sun, G. Arsenic contamination and arsenicosis in China. Toxicol. Appl. Pharmacol. 2004, 198, 268 271.

48. Xiao, X.; Chen, T.; Liao, X.; Wu, B.; Yan, X.; Zhai, L.; Xie, H.; Wang, L. Regional distribution of arsenic contained minerals and arsenic pollution in China. Geogr. Res. 2008, 1, 021.

49. Rodríguez-Lado, L.; Sun, G.; Berg, M.; Zhang, Q.; Xue, H.; Zheng, Q.; Johnson, C.A. Groundwater arsenic contamination throughout China. Science 2013, 341, 866-868.

50. Wen, D.; Zhang, F.; Zhang, E.; Wang, C.; Han, S.; Zheng, Y. Arsenic, fluoride and iodine in groundwater of China. J. Geochem. Explor. 2013, 135, 1-21.

51. Singh, B.R.; McLaughlin, M.J. Cadmium in Soils and Plants; Springer: Dordrecht, The Netherlands, 1999.

52. Liu, S.J.; Ou, L.M. Status of zinc smelting in China. Conserv. Util. Mine Res. 2003, 6, 36-40.

53. Lei, M.; Zeng, M.; Zheng, Y.M.; Liao, M.H.; Zhu, Y. Heavy metals pollution and potential ecological risk in paddy soils around mine areas and smelting areas in Hunan Province. Acta Sci. Circumst. 2008, 28, 1212-1220.

54. Cheng, S. Heavy metal pollution in China: Origin, pattern and control. Environ. Sci. Pollut. Res. 2003, 10, 192-198.

55. Rong, W.; Zhou, Q. Soil pollution processes, their affecting factors, and phytoremediation of chromium slag heads: A review. Chin. J. Ecol. 2010, 29, 598-604.

56. Jiang, G.-B.; Shi, J.-B.; Feng, X.-B. Mercury pollution in China. Environ. Sci. Technol. 2006, 40, 3672-3678.

57. Hu, D.; Zhang, W.; Tong, Y.; Wang, X. China Counties Mercury discharge investigation. http://cpfd.cnki.com.cn/Article/CPFDTOTAL-ZGDQ201107001154.htm. (accessed 1 October 2014)

58. Wu, L.; Zhao, D.; Zhang, D.; Wang, Z.; Zhang, X. Concentration and fluxes of total mercury at a forest catchment and an urban area in Chongqing City. Resour. Environ. Yangtze Basin 2006, 15, 399-404.

59. Ding, X.; Chen, L.; Zhang, W.; Xu, Z.; Peng, X.; Shang, L. Preliminary Study on Pollution Status and Assessment of Mercury in Sediment from the Beijiang River. J. Agro-Environ. Sci. 2010, 2 , $357-362$.

60. Zhang, Z.; Li, D.; Xu, Z. Present Conditions, Reasons and Measures of Lead Pollution in China. Environ. Protect. Sci. 2005, 4, 41-42.

61. Zhang, X.; Yang, L.; Li, Y.; Li, H.; Wang, W.; Ye, B. Impacts of lead/zinc mining and smelting on the environment and human health in China. Environ. Monit. Assess. 2012, 184, 2261-2273.

62. Lin, Y. Pollution of Jinjian Copper in Chifeng City caused local residents abnormal blood lead levels. Available online: http:/hj.ce.cn/gdxw/201309/12/t20130912_1091113.shtml (accessed on 12 December 2014).

63. Bale, R. China's other pollution problem-its soil. The Center for Investigative Reporting. http://www.environmentmagazine.org/Archives/Back\%20Issues/March-April\%202010/made-inchina-full.html (accessed on 25 October 2014). 
64. Tan, D. Heavy Metals \& Agriculture. China Water Risk Review. http://chinawaterrisk.org/ resources/analysis-reviews/heavy-metals-agriculture/ (accessed on 30 July 2014).

65. Wen, B.; Yang, L. A review of heavy metal contaminations in urban soils, urban road dusts and agricultural soils from China. Microchem. J. 2010, 94, 99-107.

66. United Nations Environment Program. Minamata Convention Agreed by Nations. Available online: http://www.unep.org/newscentre/default.aspx?DocumentID=2702\&ArticleID=9373 (accessed on 10 June 2014).

67. Cole, S. Foxconn building 500K iPhone 5s units for Apple per day with nonstop production lines. Available online: http://appleinsider.com/articles/13/11/27/foxconn-building-500k-iphone-5sunits-for-apple-per-day-with-nonstop-production-lines (accessed on 14 December 2014).

68. Stanway, D. The Obstacle to Treating China's Contaminated Soil is Finding Someone to Pay. Available online: http://uk.reuters.com/article/2014/09/16/us-china-pollution-soil-idUKKBN0HB2IX20140916 (accessed on 12 December 2014).

69. Changde Bureau of Land and Resources. The Overall Plan of Mineral Resources. http:/gtj.changde.gov.cn/art/2011/1/17/art_29010_726293.html (accessed on 1 December 2014).

70. Liu, J.; Zhang, X.-H.; Tran, H.; Wang, D.-Q.; Zhu, Y.-N. Heavy metal contamination and risk assessment in water, paddy soil, and rice around an electroplating plant. Environ. Sci. Pollut. Res. 2011, 18, 1623-1632.

71. Wang, Y.; Wang, P.; Bai, Y.; Tian, Z.; Li, J.; Shao, X.; Mustavich, L.F.; Li, B.-L. Assessment of surface water quality via multivariate statistical techniques: A case study of the Songhua River Harbin region, China. J. Hydro-Environ. Res. 2013, 7, 30-40.

(C) 2015 by the authors; licensee MDPI, Basel, Switzerland. This article is an open access article distributed under the terms and conditions of the Creative Commons Attribution license (http://creativecommons.org/licenses/by/4.0/). 